\title{
Autogenic Training as a behavioural approach to insomnia: a prospective cohort study
}

\author{
Ann Bowden ${ }^{1}$, Ava Lorenc ${ }^{2}$ and Nicola Robinson ${ }^{2}$ \\ ${ }^{1}$ Royal London Hospital for Integrated Medicine, University College London Hospitals, London, UK \\ ${ }^{2}$ Department of Allied Health Sciences, London South Bank University, London, UK
}

\begin{abstract}
Background: Insomnia is commonly associated with chronic health problems. Behavioural and cognitive factors often perpetuate a vicious cycle of anxiety and sleep disturbance, leading to long-term insomnia. National Institute for Health and Clinical Excellence currently recommends behavioural approaches before prescribing hypnotics. Behavioural approaches aim to treat underlying causes, but are not widely available. Research usually includes patients diagnosed with insomnia rather than secondary, co-morbid sleep- related problems. Aim: To examine the effectiveness of autogenic training (AT) as a non-drug approach to sleep-related problems associated with chronic ill health. Design: Prospective pre- and post-treatment cohort study. Setting: AT centre, Royal London Hospital for Integrated Medicine, University College London Hospitals NHS Foundation Trust. Methods: All patients referred for AT from April 2007 to April 2008 were invited to participate. Participants received standard 8-week training, with no specific focus on sleep. Sleep questionnaires were administered at four time points, 'Measure Your Medical Outcome Profile' (MYMOP) and Hospital Anxiety and Depression Scale, before and after treatment. Results before and after treatment were compared. Camden and Islington Community Local Research and Ethics Committee approved the study. Results: The AT course was completed by 153 participants, of whom $73 \%$ were identified as having a sleep-related problem. Improvements in sleep patterns included: sleep onset latency $(P=0.049)$, falling asleep quicker after night waking $(P<0.001)$, feeling more refreshed $(P<0.001)$ and more energised on waking $(P=0.019)$. MYMOP symptom, well-being, anxiety and depression scores significantly improved (all $P<0.001$ ). Conclusion: This study suggests that AT may improve sleep patterns for patients with various health conditions and reduce anxiety and depression, both of which may result from and cause insomnia. Improvements in sleep patterns occurred despite, or possibly due to, not focusing on sleep during training. AT may provide an approach to insomnia that could be incorporated into primary care.
\end{abstract}

Key words: autogenic training; behavioural approach; insomnia; sleep

Received 17 February 2010; accepted 11 April 2011; first published online 26 July 2011 
Sleep disturbances are considered insomnia once they become chronic. This may include difficulty in falling asleep, waking up frequently and waking up feeling un-refreshed (Morgan, 2008). Insomnia is associated with impaired social functioning, anxiety, delayed recovery from acute illness, depression and many non-specific physical symptoms (Luthe and Schultz, 1969; Morgan, 2008). Thus, it is costly both financially and in its impact on physical and psychological well-being (Chilcott and Shapiro, 1996; Szuba et al., 2003).

A number of factors are associated with the increased risk of long-term sleep disturbance: high levels of psychological and physical arousal; a worrisome cognitive style (often familial); being female or of older age; individuals with long-term ill health; and those providing care at home for a dependent relative or spouse (Morgan, 2008).

The most common causes of acute insomnia are loss through death, separation or divorce, physical illness, mental or emotional trauma (Szuba et al., 2003). The acute episode may need short-term medication, but for most people with appropriate support there will be resolution over time. For others, although the precipitating event has resolved, the sleep disturbance continues and it is at this point that cognitive and behavioural factors perpetuate the problem (Spielman et al., 1987). Maladaptive habits and unhelpful beliefs establish a vicious cycle in which anxiety about not sleeping becomes the focus of attention. Patients report that their lack of sleep makes them anxious and that their anxiety stops them from sleeping (Bowden, 2010).

Prescribing a hypnotic has been a standard solution to insomnia (Murtagh and Greenwood, 1995) and can be effective and welcomed by patients desperate for a good night's sleep. However, despite the introduction of newer, 'better', 'safer' and more expensive hypnotics over the past 50 years, they have not solved the problem of inability to sleep. A meta-analysis of hypnotics for older people with insomnia concluded that their use could not be justified in this group because of the risk of adverse effects (Glass et al., 2005). In addition, trials have shown that no drug is more effective than placebo for improving sleep, daytime functioning, cognition, falls and dependency (Glass et al., 2005). Ironically, the side effects of this group of drugs - cognitive impairment, daytime sleepiness and depression - are similar to the symptoms of insomnia (Holbrook, 2004).

Patients with sleep-related problems tend to be well informed about the pros and cons of the longterm use of hypnotics and are likely to welcome alternatives. Behavioural (non-pharmacological) approaches attempt to address the underlying cause of insomnia and include relaxation-based interventions, such as stimulus control therapy, sleep hygiene education, cognitive behavioural therapy and mindfulness-based stress reduction, often in combination (Morin et al., 1994; Szuba et al., 2003). Relaxation methods focus primarily on reducing somatic arousal and the mental arousal of thoughts and worries. These methods include autogenic training (AT), progressive muscle relaxation and biofeedback. However, behavioural treatments for insomnia are not widely available at present. To enable implementation of current NICE guidelines for treating insomnia, there would need to be an increase in the number of appropriately trained staff within the NHS (Anonymous, 2004).

AT is one of of the many complementary therapies provided at the NHS Royal London Hospital for Integrated Medicine (RLHIM). ${ }^{1}$ It is a stress management technique particularly recommended for conditions in which stress plays a major role in producing or maintaining ill health (Stetter and Kupper, 2002). AT was developed by the German physician and psychiatrist J.H. Schultz in the early twentieth century and is based on his extensive work on hypnosis and sleep.

AT is a psychophysiologically based form of autonomic self-regulation, a structured meditative practice. Here, the patient learns a set of six simple meditative exercises that focus the mind on the body's experience of relaxation, heaviness and warmth in the limbs, a calm heart beat, slower breathing, abdominal warmth and a cool forehead. This leads to a reduction in excessive sympathetic tone and a better balance between sympathetic and parasympathetic activity (Luthe and Schultz, 1969). Supporting this 'autogenic shift' is a state of 'passive awareness', which is a non-striving, non-judgmental attitude with the ability to accept 'what is' making possible the diminution of the effects of stressors both internal and external (Luthe and Schultz, 1969). Home

\footnotetext{
${ }^{1}$ Formerly the Royal London Homeopathic Hospital.
} 
practice is a key component and emphasises the autogenic aspect (auto = 'self' and genic = 'arising from'); the patient then comes to realise that it is their own process (Luthe and Schultz, 1969). Practice is an appointment with the self, and it is the patient who decides when and where to practise and how much time to devote to it (Luthe and Schultz, 1969).

AT improves sleep latency, duration, efficiency, and reduces medication, daytime dysfunction, anxiety and depression (Nicassio and Bootzin, 1974; Coursey et al., 1980; Stam and Bultz, 1986; Wright et al., 2002; Hidderley and Holt, 2004). A randomised study found that AT significantly improved sleep latency compared with placebo (Nicassio and Bootzin, 1974). Two other studies compared AT with biofeedback and client-centred therapy (Engel-Sittenfeld et al., 1980) and with biofeedback and electrosleep (Coursey et al., 1980) and found significant improvements in insomnia, but no difference between treatments. All three studies used patients with a diagnosis of functional insomnia, in contrast to this study, which uses a sample of patients with a range of health conditions with incidentally high levels of insomnia. The pragmatic nature of this study's NHS setting is also novel.

This study examines the effectiveness of AT as a self-management, non-drug approach to sleep disorders within NHS outpatient provision within the context of chronic ill health.

\section{Methods}

\section{Study design}

This was a prospective, cohort study of AT for insomnia. Ethical approval was obtained from the Camden and Islington Community Local Research and Ethics Committee (reference no. 06/Q0511/106).

The primary outcomes were related to sleep and were measured at four time points: at initial consultation, usually approximately 2.5 months before treatment (T1); at the start of treatment (T2); at the end of treatment (T3); and at followup (T4). Secondary outcomes were symptoms and well-being measured using 'Measure Your Medical Outcome Profile' (MYMOP) and anxiety and depression measured using the Hospital Anxiety and Depression Scale (HADS) at T2 and T3. Participants acted as their own controls by comparing changes in scores during pre-treatment period (T1-T2) with changes during treatment (T2-T3). The pre-treatment period (T1-T2) was approximately 2.5 months, which was considered sufficient time to show significant changes in sleep parameters for this period.

\section{Setting and sample}

The study took place in the AT department at the RLHIM, University College London Hospitals NHS Foundation Trust. Patients were referred from primary care $(35 \%)$, tertiary care $(60 \%)$ and self-referral (5\%). Referrals covered a wide range of health problems, in which stress is considered to play a major role.

All patients who chose to start an AT course between April 2007 and April 2008 were invited to participate. Inclusion criteria for the course were based on a verbal agreement to attend the course, work in a group and engage in home practice. Patients who would not be able to understand or follow the instructions were excluded. For this study, no further inclusion or exclusion criteria were applied.

\section{Intervention}

All patients referred for AT, irrespective of their presenting complaint, had an initial assessment where health problems were discussed, the principles of AT and the necessity of home practice explained and possible benefits outlined. Training took place in a group setting with six to eight participants per group, eight weekly sessions of $2 \mathrm{~h}$ and follow-up at three months after training. AT courses were delivered as standard by three experienced AT practitioners. There was no particular emphasis, discussion or recommendation for dealing with sleep-related problems other than expectation and encouragement of standard AT practice. Consistency in the study was implicit as the three practitioners used exactly the same training model (British Autogenic Society, 2009).

\section{Outcome measures}

Three outcome measures were used: for primary outcomes, a sleep questionnaire based on the Pittsburgh sleep index was used (Buysse et al., 1989), which has been shown to be valid and reliable for healthy volunteers and those with depression and 
sleep disorders (Buysse et al., 1989); for secondary outcomes, $\mathrm{MYMOP}^{2}$ - a patient-generated measure - was used, which was shown to be valid and responsive for patients in primary care and complementary therapy clinics (Paterson, 1996) and HADS $^{3}$ (Zigmond and Snaith, 1983), validated for physically ill patients (Herrmann, 1997). The sleep questionnaire included the following aspects: time taken to fall asleep (sleep latency), ${ }^{4}$ number of night-time awakenings, ${ }^{2}$ difficulties in getting back to sleep, ${ }^{2}$ total sleep time, ${ }^{2}$ feeling refreshed on waking, ${ }^{2}$ dream recall ${ }^{2}$ and previous day's energy. ${ }^{2}$ Questionnaires also contained open-ended questions about patients' perceived reasons for sleeprelated problems, as well as on the effects of AT on sleep. Participants completed the standard AT medical history form and feedback forms.

Participants also received a study information pack and signed a consent form at the start of training.

\section{Data analysis}

Sleep data for the pre-treatment period (T1-T2) were compared with data for the treatment period (T2-T3). For MYMOP and HADS, scores at T2 and T3 were compared. Paired $t$-tests were used for normally distributed data (continuous variables and interval data). Non-parametric tests were used for non-normally distributed data: Wilcoxon signed-ranks test for interval data; and McNemar's test for interval variables with inconsistent intervals. In addition, an intention-to-treat analysis was performed, imputing missing values with the last available value carried forward. Analysis was performed using SPSS version 15 (SPSS Inc.).

\section{Results}

A total of 289 patients were referred to the AT service during the study period. Of these referrals, 84 did not start the course because of a variety of reasons including personal choice, and being unable to commit. Data are presented for the total of 153 participants who completed the AT course, that is, completed all eight sessions and one or more questionnaires at T3 (52 started but

\footnotetext{
${ }^{2}$ Ordered categorical variable with consistent categories.

${ }^{3}$ Continuous variable.

${ }^{4}$ Ordinal variable categorised as deteriorated/stayed the same/ improved.
}

Table 1 Demographic characteristics of participants

\begin{tabular}{|c|c|c|}
\hline & $\begin{array}{l}\text { Completed } \\
\text { course } \\
(n=153)\end{array}$ & $\begin{array}{l}\text { Did not } \\
\text { complete } \\
\text { course } \\
(n=52)\end{array}$ \\
\hline & $\%(n)^{\mathrm{a}}$ & $\%(n)^{\mathrm{a}}$ \\
\hline \multicolumn{3}{|l|}{ Gender } \\
\hline Female & 75 (115) & $83(43)$ \\
\hline Male & $18(28)$ & $15(8)$ \\
\hline Missing & (10) & (1) \\
\hline \multicolumn{3}{|l|}{ Marital status } \\
\hline Single & $43(61)$ & $33(17)$ \\
\hline Married & $26(37)$ & $27(14)$ \\
\hline Divorced & (11) & (4) \\
\hline Widowed & (9) & (2) \\
\hline Cohabiting & (7) & (2) \\
\hline Missing & $12(35)$ & $25(13)$ \\
\hline \multicolumn{3}{|l|}{ Education } \\
\hline Primary school & (1) & 0 \\
\hline Secondary school & $16(25)$ & $12(6)$ \\
\hline Further education & $66(101)$ & $79(35)$ \\
\hline Missing & (26) & $21(11)$ \\
\hline \multicolumn{3}{|l|}{ Age (years) } \\
\hline$<18$ & (1) & 0 \\
\hline $19-29$ & $8(9)$ & $8(4)$ \\
\hline 30-39 & $16(20)$ & $25(13)$ \\
\hline $40-49$ & $30(38)$ & $12(6)$ \\
\hline $50-59$ & $26(33)$ & $25(13)$ \\
\hline $60-69$ & $14(17)$ & (2) \\
\hline $70-79$ & (7) & (2) \\
\hline Missing & (28) & $23(12)$ \\
\hline \multicolumn{3}{|l|}{ Medication ${ }^{b}$} \\
\hline Homeopathic & $29(32)$ & $30(10)$ \\
\hline Antidepressants & $22(23)$ & $21(7)$ \\
\hline Cardiovascular & $22(23)$ & $21(7)$ \\
\hline Vitamins/minerals & $13(14)$ & (2) \\
\hline Gastrointestinal & $12(12)$ & $18(6)$ \\
\hline Hypnotics & $10(11)$ & $18(6)$ \\
\hline Endocrine (thyroid, diabetes) & $10(11)$ & $18(6)$ \\
\hline NSAIDs & $(10)$ & 0 \\
\hline Anxiolytics & (8) & (1) \\
\hline Respiratory & (7) & 0 \\
\hline Neurological & (4) & 0 \\
\hline Other & $14(15)$ & $18(6)$ \\
\hline
\end{tabular}

NSAIDs $=$ non-steroidal anti-inflammatory drugs.

${ }^{a}$ Percentage was not calculated when $n<10$.

${ }^{b}$ Percentage of cases, many were on more than one type of medication.

did not complete). Attrition at follow-up was high (only $32 \%$ of the 153 provided data at T4), and therefore no follow-up data are presented. There were 102 completed sets of sleep questionnaires, that is, 119 for MYMOP and 138 for HADS. Table 1 provides demographic characteristics of 
participants who completed the course and those who did not complete.

The average length of pre-treatment period was 2.6 (SD 2.08) months, the average treatment period was 1.9 (SD 0.69) months and the average follow-up period was 3.69 (SD 2.19) months.

\section{Presenting health complaints}

The most common presenting complaints of those who completed the course $(n=153)$ were anxiety/depression (64\% of cases), cardiovascular disorders, mostly hypertension (15\%), insomnia $(13 \%)$, gynaecological problems, including premenstrual tension, polycystic ovaries, endometriosis and infertility (10\%); musculoskeletal disorders including rheumatoid arthritis, osteoarthritis, fibromyalgia, pain tension syndrome $(11 \%)$; and neurological disorders including multiple sclerosis and Parkinson's disease (6\%). Associated problems included family and relationship dysfunction (40\%), family illness or death (39\%) and employment problems $(12 \%)$.

\section{Frequency of and reasons for sleep-related problems}

A total of 112 (73\% of those who completed the course) participants reported having a sleep-related problem: 17 as their presenting complaint; 95 on the pre-course questionnaire or sleep questionnaire.

The reasons participants gave for their sleeprelated problems (open-ended question) were: worry/can't switch off $(21 \%)$, stress $(16 \%)$ or anxiety/depression (15\%). Participants also reported pain, tension, family troubles, noise disturbances, snoring, menopausal flushes, work worries, medication, shift work, irritable bowel syndrome and bladder symptoms, reflux and nightmares as reasons for not sleeping.

\section{Sleep changes}

Comparing changes in the pre-treatment period (T1-T2) with changes in the treatment period (T2-T3), there were significant improvements for the primary outcomes of: time taken to fall asleep; difficulty getting back to sleep; energy levels; dream recall and feeling refreshed upon waking (Table 2). Analysis was repeated using intention-to-treat analysis, imputing missing values with the most recent data available, which increased the total number of cases to 121 - time taken to fall asleep was no longer significant; difficulty getting back to sleep, feeling refreshed, dream recall and energy all remained significant; total hours asleep and number of night-time awakenings remained non-significant.

\section{Qualitative comments and feedback forms}

The comments in Box 1 show how participants appreciated AT as a self-management tool often to help them get to sleep or to get back to sleep when they wake up in the night. Qualitative data have been presented in more detail elsewhere (Robinson et al., 2010).

The feedback forms indicate that one of the most important aspects of the training was group support, as well as relaxation and increased confidence.

\section{Improvements in anxiety and depression}

Anxiety/depression was reported by $64 \%$ $(n=74)$ of participants as their most important current health problem. Figure 1 compares HADS scores from T2 to T3 (HADS was not administered at T1). Significant improvements were shown with a reduction of 11.55 to 8.94 for anxiety $(95 \% \mathrm{CI}=1.950$ to $3.262, P<0.001)$ and 7.35 to $5.28(95 \% \mathrm{CI}=1.467$ to $2.664, P<0.001)$ for depression.

Typical responses on the evaluation forms (in response to questions on change of symptoms or other changes following AT) illustrated the impact of the effects of AT on anxiety and depression (Box 2)

\section{MYMOP improvements}

All MYMOP scores (symptoms 1 and 2, activity and well-being) improved significantly (all $P<0.001$ ) when comparing T2 with T3 (MYMOP was not administered at T1) (Table 3). Profile scores dropped by an average of 1.28 following treatment.

\section{Discussion}

\section{Summary of the main findings and comparison with previous literature}

This study showed significant improvements in sleep following eight sessions of AT and personal 


\begin{tabular}{|c|c|c|c|c|c|c|c|c|c|c|c|c|c|}
\hline \multirow[t]{2}{*}{ Variable } & \multicolumn{5}{|c|}{$\begin{array}{l}\text { Pre-treatment control (T1-T2; completed } \\
\text { both questionnaires, } n=125)\end{array}$} & \multicolumn{5}{|c|}{$\begin{array}{l}\text { Treatment (T2-T3; completed both } \\
\text { questionnaires, } n=111)\end{array}$} & \multirow[b]{2}{*}{$\begin{array}{l}\text { Significance test - } \\
\text { comparing changes } \\
\text { during treatment with } \\
\text { pre-treatment control- } \\
\text { and } P \text {-value (completed } \\
\text { all questionnaires, } \\
n=102 \text { ) }\end{array}$} & \multicolumn{2}{|c|}{$\begin{array}{l}\text { Intention-to-treat } \\
\text { analysis }(n=121)\end{array}$} \\
\hline & Deteriorated & $\begin{array}{l}\text { Stayed } \\
\text { the same }\end{array}$ & Improved & $\begin{array}{l}\text { Missing } \\
\text { data }\end{array}$ & $\begin{array}{l}\text { Significance } \\
\text { test and } \\
P \text {-value }\end{array}$ & Deteriorated & $\begin{array}{l}\text { Stayed } \\
\text { the same }\end{array}$ & Improved & $\begin{array}{l}\text { Missing } \\
\text { data }\end{array}$ & $\begin{array}{l}\text { Significance } \\
\text { test and } \\
P \text {-value }\end{array}$ & & $\begin{array}{l}\text { Missing } \\
\text { data }\end{array}$ & $\begin{array}{l}\text { Significance } \\
\text { test and } \\
P \text {-value }\end{array}$ \\
\hline \multirow{4}{*}{$\begin{array}{l}\text { Time taken to fall } \\
\text { asleepe } \\
\text { Number of night- } \\
\text { time awakenings } \\
\text { Time taken to get } \\
\text { back to sleep } \\
\text { Total hours asleep } \\
\text { Tot }\end{array}$} & 23 & 79 & 23 & 0 & $\begin{array}{l}\chi^{2}=12.89 \\
P=0.33\end{array}$ & 9 & 56 & 44 & 2 & $\begin{array}{l}\chi^{2}=29.897 \\
P=0.001 *\end{array}$ & $\chi^{2}=7.84, P=0.049^{*}$ & 0 & \multirow{7}{*}{$\begin{array}{l}x^{2}=6.84, \\
P=0.77^{* * *} \\
\chi^{2}=7.849, \\
P=0.49^{* * *} \\
Z=-3.906, \\
P<0.001^{* * * * * *} \\
95 \% \\
C l=-0.42 \text { to } \\
0.21, \\
P=0.4988^{* * *} \\
Z=-3.039, \\
P<0.002^{* * * * * *} \\
Z=-1.960, \\
P=0.050^{* * * * * *} \\
95 \% \\
C l=-1.38 \text { to } \\
-0.03 \\
P=0.041^{* * * * * *}\end{array}$} \\
\hline & 29 & 71 & 23 & 2 & $\begin{array}{l}\chi^{2}=5.58 \\
P=0.70\end{array}$ & 11 & 64 & 34 & 2 & $\begin{array}{l}\chi^{2}=19.20 \\
P=0.038^{*}\end{array}$ & $\chi^{2}=6.80, P=0.079$ & 1 & \\
\hline & 22 & 85 & 18 & 0 & $\begin{array}{l}Z=-0.47 \\
P=0.64\end{array}$ & 1 & 63 & 40 & 7 & $\begin{array}{l}Z=-4.87 \\
P<0.001\end{array}$ & $Z=-4.47, P<0.001^{*}$ & 4 & \\
\hline & 33 & 66 & 25 & 1 & $\begin{array}{l}95 \% \\
\mathrm{Cl}=-0.15 \\
\text { to } 0.22 \\
P=0.73\end{array}$ & 15 & 55 & 41 & 0 & $\begin{array}{l}95 \% \\
\mathrm{Cl}=-0.46 \text { to } \\
-0.01 \\
P=0.044^{*}\end{array}$ & $\begin{array}{l}95 \% \mathrm{Cl}=-0.49 \text { to } 0.26 \\
P=0.55\end{array}$ & 0 & \\
\hline \multirow{2}{*}{$\begin{array}{l}\text { Feeling refreshed } \\
\text { on waking upd } \\
\text { Dream recal }\end{array}$} & 42 & 32 & 50 & 1 & $\begin{array}{l}Z=-1.39 \\
P=0.17\end{array}$ & 18 & 15 & 68 & 10 & $\begin{array}{l}Z=-5.93 \\
P=0.901^{*}\end{array}$ & $Z=3.92, P<0.001^{*}$ & 7 & \\
\hline & 30 & 81 & 11 & 3 & $\begin{array}{l}Z=-2.81 \\
P=0.005^{*}\end{array}$ & 12 & 69 & 21 & 9 & $\begin{array}{l}Z=-1.39 \\
P<0.16\end{array}$ & $Z=-1.96, P=0.050^{*}$ & 10 & \\
\hline $\begin{array}{l}\text { Energy (previous } \\
\text { day) }^{c}\end{array}$ & 38 & 27 & 50 & 10 & $\begin{array}{l}95 \% \\
\mathrm{Cl}=0.41 \text { to } \\
-0.41 \\
P=0.97\end{array}$ & 21 & 23 & 56 & 11 & $\begin{array}{l}95 \% \\
\mathrm{Cl}=-1.48 \text { to } \\
-0.56 \\
P<0.001^{*}\end{array}$ & $\begin{array}{l}95 \% \mathrm{Cl}=-1.76 \text { to }-0.17 \\
P=0.019^{*}\end{array}$ & 2 & \\
\hline
\end{tabular}

*Significant results; ${ }^{* *}$ lost significance; ${ }^{* * *}$ no change.

$\mathrm{T} 1$ = before treatment; $\mathrm{T} 2=$ at the start of treatment; $\mathrm{T} 3=$ at the end of treatment.

bcNemars test.

${ }^{c}$ Paired $t$-test.

${ }^{\mathrm{d}}$ Wilcoxon signed-rank test. 


\section{Box 1 Quotes from the sleep questionnaire and evaluation form}

'I worry less about sleeping'

'It has definitely helped me to get better quality of sleep'

'It has given me a coping mechanism for handling insomnia, knowledge that I possess this power is a great reassurance and calming in itself. It prevents a vicious cycle of insomnia and panic about having insomnia'

'I have noticed I wake feeling more refreshed. Knowing I can use AT to get back to sleep if I need to'

'Very good - go off to sleep almost straight away after AT exercise - very relaxing'

'I am sleeping undisturbed!! AMAZING'

'Outstanding! I was astounded but very pleased with the almost immediate effect AT had on my ability to fall asleep, its made a huge difference'

'An excellent effect. It has been such a long time since I have had the pleasure and benefits of a 'good' restful sleep. Long may it last'

'I am more able to put the day's activities aside and relaxed. I feel calmer when I go to bed'

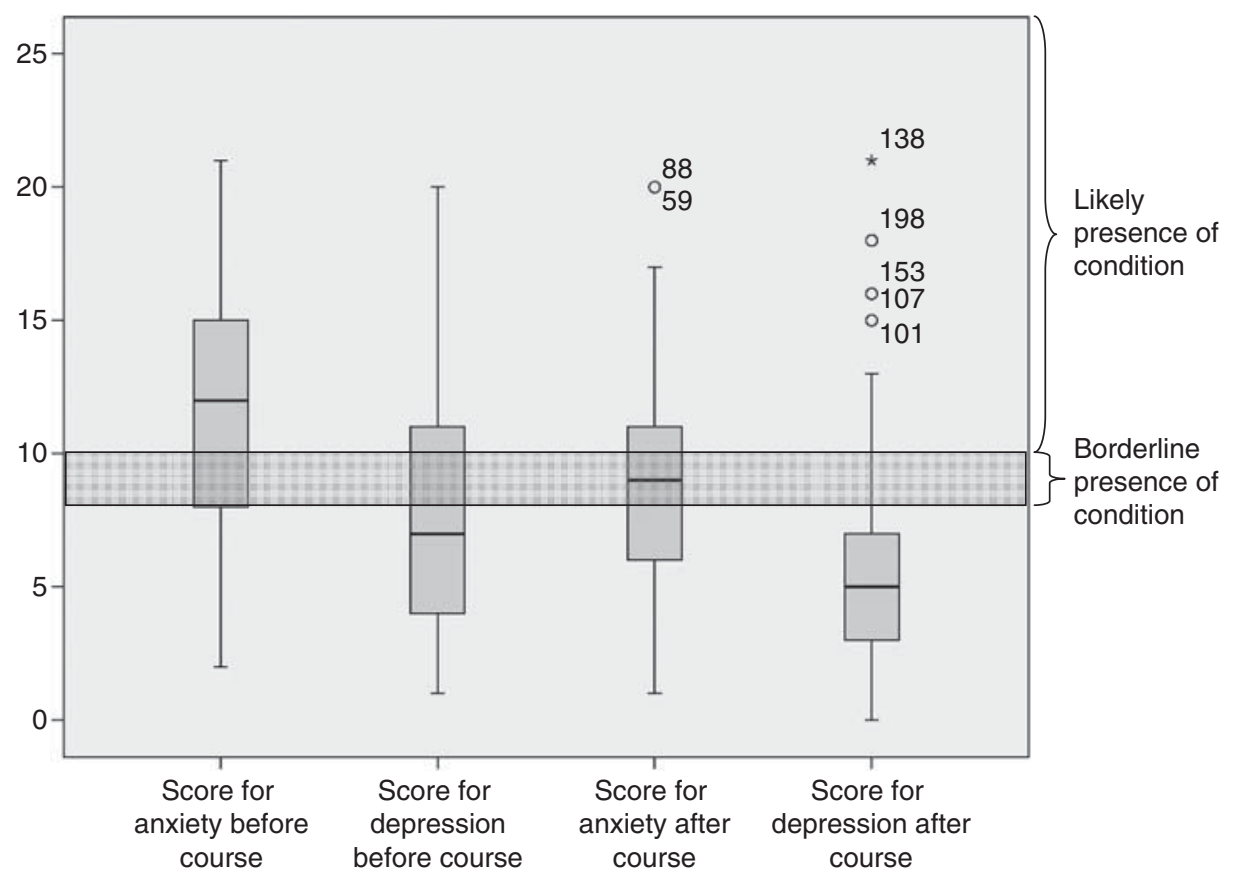

Figure 1 Boxplot showing median scores and interquartile ranges for HADS scores

daily home AT practice. These included: falling asleep quicker; getting back to sleep quicker after waking up in the night; feeling refreshed on waking up (most frequent improvement) and having more energy on waking up. When missing data were included in the intention-to-treat analysis, only results for time taken to fall asleep were affected. MYMOP scores also showed significant improvement in symptoms and well-being.

Recruitment for the study was not restricted to patients presenting with insomnia; however, $73 \%$ of the patients did in fact have a sleep-related 
problem, and over half had co-morbid insomnia (a sleep-related problem secondary to their presenting complaint). Chronic symptoms can produce physiological and cognitive changes that are similar to those experienced as a result of prolonged stress (Sadigh, 2001). It is, therefore, not surprising that our findings confirm that people with chronic health problems often do not sleep, which then becomes an additional burden (Katon et al., 2007).

Research generally focuses on individuals with primary insomnia, who are otherwise healthy and not on medication (Murtagh and Greenwood, 1995). In this study, participants were suffering from a wide range of chronic conditions, which included a high incidence of insomnia. Improvements in sleep occurred despite not specifically focusing on the

\section{Box 2 Quotes on changes following AT}

'Feel a lot calmer and more centred/grounded' 'Feel much happier'

'I'm not so anxious... The repetitive thought are almost nil'

'I attract more positive responses from others. Calmness and lack of panic are frequently remarked upon by family and close friends' 'I can control my panic attacks'

'I am coping better as I have a more positive outlook'

'more control over my surroundings and a feeling of assertiveness with confidence' 'able to handle stressful situations better, generally feel calmer' problem. Any discussion about sleep was instigated by the participants; for example, reporting their first good night's sleep for a long time, or starting an AT exercise on going to bed and sleeping through until morning. In a group setting, these comments encourage and enhance the effects of AT practice and its possibilities.

Our findings support observations by AT therapists that AT improves the sleep pattern. Some trainees who have not mentioned a sleep-related problem recognise the fact that they have a sleep deficit. Others find that AT exercise results in feeling refreshed with renewed energy. It has been observed in trainees with or without sleep disorders that after a few weeks of AT practice changes in sleeping patterns occur, primarily falling asleep more quickly, feeling more refreshed in the morning, improved mood and increased recall of dreams (Luthe and Schultz, 1969).

Trainees report that they find their own way of practising at home, but the most significant changes are noticed when they practise regularly during the day (Luthe and Schultz, 1969). Each session acts as a 'power' rest and breaks up the vicious cycle of increasing mental and physical tension, restlessness and anxiety, which can build up during the day and prevent sleep (Luthe and Schultz, 1969).

The value placed on the group support element of AT by participants highlights that the essence of the AT group process is acceptance, respect and trust between the therapist and the individual and between the group members themselves (Bowden, 2010). Many participants who embarked on this AT course were experiencing great stresses in their lives and felt isolated with their symptoms. Feedback and

Table 3 MYMOP scores ${ }^{a}$ before versus after treatment

\begin{tabular}{|c|c|c|c|}
\hline \multirow[t]{2}{*}{ MYMOP } & \multirow{2}{*}{$\frac{\text { Before treatment }}{\text { Mean (SD) }}$} & \multirow{2}{*}{$\frac{\text { After treatment }}{\text { Mean (SD) }}$} & \multirow{2}{*}{ 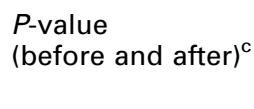 } \\
\hline & & & \\
\hline Symptom 1 & $3.97(1.310)$ & $3.00(1.408)$ & $<0.001$ \\
\hline Symptom 2 & $3.90(1.133)$ & $2.73(1.256)$ & $<0.001$ \\
\hline Activity & $4.09(1.301)$ & $2.71(1.376)$ & $<0.001$ \\
\hline Well-being & $3.43(1.187)$ & $2.54(1.231)$ & $<0.001$ \\
\hline Profile score ${ }^{b}$ & $3.90(0.932)$ & $2.62(0.945)$ & $<0.001$ \\
\hline
\end{tabular}

MYMOP = Measure Your Medical Outcome Profile.

a Scale from 0 to 6,0 is good as it can be, 6 is as bad as it can be.

b Mean of all other scores.

cWilcoxon signed-rank test.

Primary Health Care Research \& Development 2012; 13: 175-185 
modelling from other group members provide opportunities for social and cognitive reframing, and from this can ensue the development of greater self-esteem and self-confidence.

\section{Strengths and limitations of the study}

Unlike most studies on treatments for insomnia, participants for this study were not chosen for their sleep-related problems, yet there was a high prevalence of co-morbid insomnia. This recruitment strategy allowed us to show that AT can improve sleep despite sleep not being the focus of training.

The study is subject to a number of limitations. Participants acted as their own controls, which cannot reliably confirm causal effects and may be subject to contamination by historical events. However, we felt that it would be unethical to randomise patients to 'treatment' or 'no treatment' groups as the study was pragmatic, taking place within a normal NHS clinic, in which the act of volunteering for the study was inherent in the expectation of doing the training. Another possible option would have been to use patients who declined the training as controls; however, this would have inevitably introduced confounding variables. We, therefore, chose to use the pre-treatment period as the control, which is an accepted methodology, and we believe that this is a legitimate and valid design for psychological and sociological research within service evaluation.

It is possible that those who did not benefit from AT left the course or the study. However, intention-to-treat analysis (although this only added 19 cases) shows that the significance of results for six out of seven variables did not change. Dropout was usually due to patients' ill health, problems involved in travelling to the hospital, unforeseen personal or work demands or patients failing to engage with the process.

There were a number of missing and incomplete questionnaires that limited the findings. This was due to the pragmatic nature of the study, which took place in a time-limited NHS clinic. There were additional missing data for time taken to get back to sleep and dream recall, probably because of questionnaire layout and the inevitability of participants not answering all the questions on all questionnaires. A number of questions on the sleep questionnaire were categorical, and thus may not have been sensitive enough to identify smaller improvements, particularly dream recall.

A further limitation was the variation in the length of the pre-treatment and follow-up periods $(\mathrm{SD}=2.08$ and 2.19 months, respectively). Future research may need to improve participant motivation regarding return of questionnaires and monitoring of individual's questionnaire completion, a common difficulty when using multiple questionnaires in a clinical setting.

Attrition at follow-up (T4) was high, and therefore results could not be calculated, although intention-to-treat analysis suggests that the effect of dropout was minimal. The study took place at an NHS specialist hospital in Central London, and thus the study population was exclusive to those patients who could be referred and could travel (often long distances) to attend the sessions. Although previous research has shown that outcomes are not related to age or gender (Morin et al., 1994), it is likely that providing AT locally would result in its uptake by a wider patient population and in better follow-up.

The group element of the training was valued by participants; however, there is a chance that interaction between participants within groups biased the results by increasing the chance of a type I error, although participants did complete questionnaires by themselves, mostly at home (Baldwin et al., 2005).

\section{Clinical implications}

The current NICE guidelines for treating insomnia in primary care recommend that behavioural approaches be considered before prescribing a hypnotic (NICE, 2005). The results of this study show improvements in sleep, anxiety and depression and general well-being in patients who completed an AT course in an NHS setting.

Participants recognised improvements and described AT as a therapeutic tool, which is particularly helpful for inducing sleep and for getting back to sleep after waking up in the night. Fitting AT practice into busy lives can highlight behavioural and cognitive patterns that are maintaining ill health. With self-observed improvements in symptoms, patients are encouraged to see AT practice as a personal, internal, therapeutic resource that they can use as required. Continued practice is essential if health benefits are to be maintained. 
Dr Ann Bowden, previously a general practitioner, has considerable experience of the positive results of offering the training in General Practice and of introducing AT into primary care (Author, 2010). A two-year pilot project, commissioned by a Primary Care Group from the RLHIM, for anxiety, panic attacks and insomnia, showed similar results to the current study (Author, 2006).

\section{Future research}

This study shows very promising results for using AT to treat co-morbid insomnia. Studies using randomisation, separate control groups and comparison with other behavioural interventions and hypnotics are now needed. Studies focusing on specific disease populations could provide more insight into the treatment of insomnia as a secondary component.

\section{Conclusion}

This study suggests that AT can improve sleep patterns in participants with a wide range of health conditions and may reduce depression and anxiety, which can both result from and cause insomnia. The improvements in sleep were despite, and possibly due to, not focusing on sleep problems during training. This highlights how observation of nonspecific effects of an intervention can measure the holistic effect rather than simply the evaluation of effects on the presenting complaint.

It also suggests that, as a drug-free treatment, AT may provide a more acceptable option for patients with chronic insomnia than taking hypnotics (Morin et al., 1994). As a structured eightsession group-based course, it also has the potential to be cost effective in the long term (Anonymous, 2004).

\section{Acknowledgements}

This study received $£ 1000$ from the RLHIM League of Friends. The authors have no conflict of interest to declare. The authors thank Tamara Callea and Chris Perrin, two of the AT therapists, who were generous with their time and provided invaluable help and support. They also thank Tom Kirby, Clinical Governance Manager, for support in setting up the project, and the RLHIM League of Friends for their donation to the study.

Primary Health Care Research \& Development 2012; 13: 175-185
The authors are very grateful to the patients who took part.

\section{References}

Anonymous. 2004: What's wrong with prescribing hypnotics? Drug and Therapeutics Bulletin 42, 89-93.

Bowden, A. 2006: AT as a non-drug approach to anxiety, panic attacks and insomnia. Journal of Holistic Care 1.

Baldwin, S.A., Murray, D.M. and Shadish, W.R. 2005: Empirically supported treatments or type I errors? Problems with the analysis of data from group-administered treatments. Journal of Consulting and Clinical Psychology 73, 924-35.

British Autogenic Society. 2009: www.autogenic-therapy. org.uk

Bowden, A. 2010: Clinical roundup: how do you treat insomnia in your practice?: Autogenic Training. Alternative and Complementary Therapies 16, 299-305.

Buysse, D.J., Reynolds, C.F. III, Monk, T.H., Berman, S.R. and Kupfer, D.J. 1989: The Pittsburgh Sleep Quality Index: a new instrument for psychiatric practice and research. Psychiatry Research 28, 193-213.

Chilcott, L.A. and Shapiro, C.M. 1996: The socioeconomic impact of insomnia: an overview. Pharmaeconomics 10, $1-14$.

Coursey, R.D., Frankel, B.L., Gaarder, K.R. and Mott, D.E. 1980: A comparison of relaxation techniques with electrosleep therapy for chronic, sleep-onset insomnia a sleep-EEG study. Biofeedback and Self Regulation 5, 57-73.

Engel-Sittenfeld, P., Engel, R., Huber, H. and Zangl, K. 1980: Wirkmechanismen psychologischer Therapieverfahren bei der Behandlung chronischer Schlafstorungen [Effects of psychological therapy in the treatment of insomnia]. Zietschrift fur Klinische Psychologie 9, 34-52.

Glass, J., Lanctot, K.L., Herrmann, N., Sproule, B.A. and Busto, U.E. 2005: Sedative hypnotics in older people with insomnia: meta-analysis of risks and benefits. British Medical Journal 331, 1169.

Herrmann, C. 1997: International experiences with the Hospital Anxiety and Depression Scale-a review of validation data and clinical results. Journal of Psychosomatic Research 42, 17-41.

Hidderley, M. and Holt, M. 2004: A pilot randomized trial assessing the effects of autogenic training in early stage cancer patients in relation to psychological status and immune system responses. European Journal of Oncology Nursing 8, 61-65.

Holbrook, A.M. 2004: Editorial: treating insomnia. British Medical Journal 39.

Katon, W., Lin, E.H. and Kroenke, K. 2007: The association of depression and anxiety with medical symptom burden in patients with chronic medical illness. General Hospital Psychiatry 29, 147-55. 
Luthe, W. and Schultz, J.H. 1969: Autogenic therapy: applications in psychotherapy. New York: Gronne Statton.

Morgan, K. 2008: Patients with insomnia should recieve sleep hygeine advice. Guidelines in Practice 11, 35-41.

Morin, C.M., Culbert, J.P. and Schwartz, S.M. 1994: Nonpharmacological interventions for insomnia: a metaanalysis of treatment efficacy. American Journal of Psychiatry 151, 1172-80.

Murtagh, D.R. and Greenwood, K.M. 1995: Identifying effective psychological treatments for insomnia: a metaanalysis. Journal of Consulting and Clinical Psychology 63, 79-89.

Nicassio, P. and Bootzin, R. 1974: A comparison of progressive relaxation and autogenic training as treatments for insomnia. Journal of Abnormal Psychology 83, 253-60.

National Institute for Health and Clinical Excellence (NICE). 2005: Insomnia - newer hypnotic drugs: Guidance TA77. London: NICE website Guidance TA77.

Paterson, C. 1996: Measuring outcomes in primary care: a patient generated measure, MYMOP, compared with the SF-36 health survey. British Medical Journal 312, 1016-020.

Robinson, N., Bowden, A. and Lorenc, A. 2010: Can improvements in sleep be used as an indicator of the wider benefits of Autogenic Training and CAM research in general? European Journal of Integrative Medicine 2, $57-62$.

Sadigh, M.R. 2001: Autogenic Training: a mind body approach to the treatment of fibromyalgia and chronic pain syndromes. Philadelphia, PA: Haworth Medical Press.

Spielman, A.J., Carruso, L.S. and Glovinsky, P.B. 1987: A behavioural perspective on insomnia treatment. The Psychiatric Clinics of North America 10, 541-53.

Stam, H.J. and Bultz, B.D. 1986: The treatment of severe insomnia in a cancer patient. Journal of Behaviour Therapy and Experimental Psychiatry 17, 33-37.

Stetter, F. and Kupper, S. 2002: Autogenic training: a metaanalysis of clinical outcome studies. Applied Psychophysiology and Biofeedback 27, 45-98.

Szuba, M.P., Kloos, J.D. and Dinges, D.F. 2003: Insomnia: principles and management. Cambridge: Cambridge University Press.

Wright, S., Courtney, U. and Crowther, D. 2002: A quantitative and qualitative pilot study of the perceived benefits of autogenic training for a group of people with cancer 6 . European Journal of Cancer Care (England) 11, 122-30.

Zigmond, A.S. and Snaith, R.P. 1983: The hospital anxiety and depression scale. Acta Psychiatrica Scandinavica 67, $361-70$ 